\title{
A (RE) DESCOBERTA DO CONHECIMENTO PELA “ALFABETIZAÇÃO TECNOLÓGICA” DOCENTE
}

SOUZA, Carlos Henrique Medeiros ${ }^{1}$

Recebido em: $2008-11-25$

Aprovado em: 2009-02-01

ISSUE DOI: 10.3738/1982.2278.156

RESUMO: O presente texto procura retratar a importância e relevância dos cursos de formação de professores mediante a utilização das Novas Tecnologias de Informação e Comunicação na educação. $\mathrm{O}$ impacto causado pelas tecnologias, não apenas na educação, mas na sociedade como um todo, é o alvo desta discussão que pretende abranger a importância da formação do professor crítico como uma forma de estabelecer uma conexão entre os anseios e as necessidades sociais e o papel da escola enquanto colaboradora na inserção do ser humano no meio social. Por este motivo, enfoca-se a idéia de que tanto a formação inicial quanto à formação continuada do professor deve ser o ponto de partida para estas transformações.

Palavras-chave: Tecnologias. Formação docente. Sociedade e informação.

SUMMARY: This text seeks to portray the importance and relevance of teacher training courses through the use of New Information and Communication Technologies in education. The impact caused by there Technologies, not only in education but in society as a whole, is the target of this text that is intended to cover the importance of teacher training as a critical way to establish a connection between the aspirations and social needs and the role of the school as a collaborator in the insertion of human beings in the social environment. For this reason, in focuses the idea that both the initial training and the continuous training of teachers should be the starting point for these changes.

Keywords: Technology. Teacher training. Society and information.

\section{AS TECNOLOGIAS E A EDUCAÇÃO: UMA RELAÇÃO INSTIGANTE E CONFLITUOSA QUE EXIGE "ALFABETIZAÇÃO TECNOLÓGICA DO PROFESSOR"}

As Tecnologias de Informação e Comunicação (TICs) vêm redimensionando a prática pedagógica costumeiramente ocorrida nos mais diversos níveis de ensino.

As implicações epistemológicas das tecnologias na educação propõem uma reestruturação radical no interior das relações acadêmicas e sociais uma vez que, não se pode atribuir a elas o poder de alterar a prática docente, mas pode ser atribuído o poder de auxiliar na construção de uma aprendizagem significativa a partir do momento em que ocorre a midiatização do ensino através das mais diversas técnicas (BELLONI,

1 Mestre em Educação / Doutor em Comunicação. Universidade Estadual do Norte Fluminense. 
2001).

O professor visto como "tecnólogo" agora desempenha dupla função: o de ser professor em toda a sua essência, e o de ser um facilitador da aprendizagem, usando de todos os meios e métodos disponíveis que possam vir a interferir em sua ação docente.

O professor passa a assumir então uma "postura de aquisição, criticidade e de dúvida diante das informações - novas e velhas - e, ao mesmo tempo, exercer papel de orientação e cooperação com os alunos. Ensiná-los a aprender e (...) aprender, ensinando". (KENSKI, 2003).

Esse desafio colocado aos educadores faz parte de uma política instalada de caráter nada recente. $\mathrm{O}$ discurso sobre o uso das tecnologias na educação não se constitui um discurso novo. Há décadas tem se tentado, mesmo sem muito sucesso, instaurar uma política de uso de recursos tecnológicos na ação dos professores de forma a proporcionar uma aprendizagem mais significativa aos educandos e, consequentemente, propor uma ação docente mediada pelo uso cada vez mais constante dos recursos tecnológicos. Podemos dizer que, com o desencadear da Tendência Tecnicista $^{2}$, houve um crescente movimento em torno da utilização de técnicas e de recursos com o objetivo de auxiliar qualitativamente o processo ensino-aprendizagem. Nunca se falou tanto em uso de recursos/técnicas.

Talvez tenha ocorrido uma má interpretação quanto à concepção do uso de recursos tecnológicos na educação e isso veio atribuindo um péssimo uso dos mesmos, fazendo com que boa parte dos professores atribuíssem a eles a "função de ensinar". Esta imagem negativa ocorre em vários setores. Podemos citar, por exemplo, o uso dos recursos audiovisuais que, de tanto serem mal utilizados em sala de aula, tornaram-se em boa parte, banalizados, desconsiderando assim a sua importância e a intenção de sua criação. A mesma falha é percebida quando se fala em construtivismo ${ }^{3}$. Por ter sido mal interpretado pela maioria dos professores, acabou sofrendo forte crítica e diante disso, a escola vem adquirindo uma cultura escolar bem distante da proposta construtivista.

O aprimoramento dessa discussão vem gerando desde então a busca por uma

\footnotetext{
2 Tendência Liberal Tecnicista propõe que o professor assuma o papel de organizar o processo de aquisição de habilidades, atitudes e conhecimentos específicos úteis e necessários para que cada indivíduo se integre na máquina do sistema global onde se visa a qualificação para o trabalho através das técnicas. O material instrucional encontra-se sistematizado em manuais, livros didáticos, nos módulos de ensino, nos dispositivos audiovisuais. Acontece então a transmissão/recepção de informações. Libâneo, J.C. Tendências pedagógicas na pratica escolar. In: Revista Nacional de Educação Cortez, nº 6, São Paulo, 1983.

3 O construtivismo, sobretudo, uma posição epistemológica, isto é, refere-se à forma como o conhecimento se origina e se modifica. Como tal não deve ser confundido com uma posição pedagógica. Delval, Juan. Teses sobre o construtivismo, in Conhecimento cotidiano, escolar e cientifico: representação e mudança.
} 
política de conscientização que tende a querer atingir a escola, em todo seu contexto, e, principalmente, os professores.

Tal necessidade fez com que a discussão ganhasse um espaço maior e que passasse, então, a pensar estas questões tão relacionadas à educação e principalmente referentes à ação docente no âmbito dos cursos de formação de professores. A formação inicial e a formação continuada passaram a vislumbrar a necessidade de propor esta "alfabetização tecnológica do professor",

Mas, será mesmo que o professor necessita desta alfabetização tecnológica? Talvez essa seja uma das maiores perguntas a serem feitas nos dias atuais, em que a mudança acelerada e o maior acesso a informações têm provocado instabilidade em todas as estruturas sociais vigentes, desde o mercado de produção, economia, saúde à escola.

O professor, mediante a necessidade e oportunidade de redimensionar, a sua prática docente podendo fazer uso das tecnologias disponíveis, encontra uma série de barreiras. Uma delas, e talvez uma das mais comprometedoras, está diretamente ligada à concepção de educação, escola e prática docente. Porque se resolve adotar novos meios de trabalhar se as escolas ainda operam em velhas estruturas? E, se essas velhas estruturas não proporcionam um ambiente motivador de mudanças, para que pensar, então, em dinamizar a prática docente, em um espaço nada facilitador destas mudanças? Cabe ainda um terceiro questionamento: se a prática docente aliada às velhas estruturas das escolas, não proporciona momentos de reflexão para se redimensionar o processo ensino-aprendizagem, então, qual será o futuro da educação em tempos de instabilidade social, acesso cada vez maior às informações e, consequentemente, a desapropriação de sua própria identidade, uma vez que a escola deixa de atender as expectativas de seu alunado, provocando assim um considerável distanciamento entre dois pólos que devem estar permanentemente conectados:

$$
\text { escola } \longrightarrow \text { sociedade. }
$$

A escola não pode ignorar o que se passa no mundo. As novas tecnologias de informação e da comunicação transformam espetacularmente não só a maneira de comunicar, mas também de trabalhar, de decidir, de pensar, e ainda, de introduzir

O conceito de alfabetização tecnológica esta diretamente relacionado a um outro conceito que vem evoluindo nas últimas décadas: Tecnologia Educacional. Para compreender o primeiro é necessário relacioná-lo a este último, tendo-se como pano de fundo a escola e a sociedade. Sampaio, 2001. 
forçosamente um novo quadro para o sistema educacional, justamente por estarem representando uma escola paralela (PRETTO, 2002). Sendo assim, a escola precisa aliar-se a elas e propor uma nova estratégia educativa, travando com elas um jogo dialético.

As respostas propõem um exercício de grande reflexão. Porém, partir da análise da vivência é algo ainda muito imaturo, tendo em vista o passo lento com o qual a educação se desenvolve no Brasil, principalmente quando se fala das TICs. Parece talvez um pouco utópico falar em tecnologias educacionais no nosso país, uma vez que muitas escolas não possuem sequer giz. Porém, enquanto existe utopia, existe a possibilidade de desvendar os mistérios que camuflam o caminhar da educação no Brasil, bem como do surgimento de novas dúvidas e inquietações que, uma vez postas em questão poderão nortear um vasto campo ainda pouco explorado.

Segundo o professor Marco Antônio da Silva ${ }^{5}$ :

Parece uma afronta, uma ironia falar das tecnologias para as escolas por este país afora onde muitas não tem giz, ou pelo menos infra-estrutura básica para fazer educação. $\mathrm{O}$ que se faz na escola inforica com todas as tecnologias digitais se faz também na escola infopobre. (grifos nosso)

Partindo destas palavras, pode-se afirmar que fazer educação não está relacionado ao uso de recursos tecnológicos avançados. Fazer educação está relacionado à forma como se utilizam os mais diversos recursos. "Isto pode acontecer até mesmo embaixo de uma árvore usando dos recursos disponíveis" (SILVA, 2003). É preciso resgatar que as tecnologias não se limitam às mais novas invenções, mas, que tecnologias são recursos utilizados para permear e mediatizar o processo ensinoaprendizagem.

Buscando então respaldo para explicar a necessidade de insistir nesta utopia, apoiamo-nos nas palavras de Eduardo Galeano, que considera a utopia como:

[...] ela está no horizonte [...]. Me aproximo dois passos, ela se afasta dois passos.

Por mais que eu caminhe, jamais a alcançarei. Para que serve a utopia? Serve para isso, para caminhar.

Sob essa perspectiva, a prática docente tem sido atingida por vários ângulos. Talvez seja difícil para educadores acreditar que a ação docente possa ser modificada diante da democratização e conscientização do uso de recursos tecnológicos na

5 Professor da Estácio de Sá em participação no Programa Salto para o Futuro - série: Integração das mídias. Canal TV Escola. Programa veiculado dia 20 de novembro de 2003 no horário das 11:00 às 12:00 horas. 
educação. Porém, esta é uma realidade e não uma utopia.

Diante desta propositura, os cursos de formação de professores (inicial ou continuada) deverão assumir uma posição autocrítica em favor da negação da exclusão tecnológica, procurando com isso atender às demandas sociais, pois a escola como subsistema interdependente da sociedade não pode deixar de ser atingida pelas mais diversas transformações e continuar a ser o utensílio artesanal que era, uma vez que deixou de responder às necessidades sociais, pedagógicas e psicológicas expressas pela nova sociedade escolar. Talvez sejamos ainda os mesmos professores. A estrutura escolar continua sendo a mesma, mas nossos alunos são outros. Vivem na chamada Sociedade da Informação, rodeados das facilidades propostas pela modernização e do aumento do fluxo não só das informações mas da própria parafernália de artefatos hoje disponíveis nos mais diversos ambientes públicos e privados.

Talvez seja necessário repensar a estrutura atual vigente nos cursos de formação de professores para que se possa agir, então, em favor da formação de sujeitos críticos de sua própria prática docente e da utilização de recursos que a permeiam sobre ela.

Segundo Kenski (2001):

Estes posicionamentos críticos em relação às tecnologias são fundamentais na orientação de um programa de formação de professores para a sociedade contemporânea, sobretudo no Brasil. Trata-se de formar professores que não sejam apenas usuários ingênuos das tecnologias, mas profissionais conscientes e críticos que saibam utilizar suas possibilidades de acordo com a realidade em que atuam.

É comum termos relações conflituosas quando falamos em tecnologias. São muitos os discursos voltados para a aparição das tecnologias como uma forma de invasão em um espaço. É justamente esta invasão que a classe docente teme. Ao falar que as tecnologias estão "invadindo a escola", causa-se um certo temor, medo, receio, angústia e, inclusive, desconforto já que nos sentimos ameaçados por essa prerrogativa.

Talvez não se possa afirmar que as tecnologias invadem o ambiente escolar, mas pode-se afirmar que estas causam mudanças significativas em diversos olhares e reflexão sobre o que vem a ser a instituição escolar e qual o papel a desenvolver mediante a sociedade que anseia não somente por transformações significativas, mas também pela maior "interatividade" e "reciprocidade" entre as ações da educação mediante seus principais parceiros: a sociedade à qual a mesma é responsável por atender.

Se as tecnologias invadem o âmbito escolar, talvez seja necessário entendê-las 
como aliadas, e não como uma escola paralela (PRETTO, 2002). Do ponto de vista significativo para a educação, integralizar as TICs no projeto pedagógico das escolas estabelecerá uma parceria e não uma competição gerada pelo mau entendimento da gestão tecnológica na educação. Mas falar sobre esta "Alfabetização Tecnológica" requer pensar a formação de professores, ou seja, as licenciaturas deverão ser repensadas. Quando Chauí fala sobre a universidade operacional ${ }^{6}$, a mesma ressalta pontos interessantes que nos fazerem concluir que realmente os cursos de formação de professores deverão ser repensados. Segundo Chauí (1999):

A docência é pensada como habilitação rápida para graduados, que precisam entrar rapidamente no mercado de trabalho do qual serão expulsos em poucos anos, pois tornam-se pouco tempo, jovens obsoletos e descartáveis [...].Desapareceu, portanto a marca essencial da docência: a formação.

Portanto, pensar na formação de professores como uma das possibilidades de inserção das tecnologias de informação e de comunicação e conseqüentemente desta alfabetização tecnológica, requer pensar um pouco qual tem sido a formação ocorrida nos últimos anos, sobretudo no Brasil.

Para nos situarmos no tempo e espaço contemporâneo daquilo que chamamos de cursos de formação de professores, podemos pensar, portanto, na formação de professores nas últimas três décadas, para, a partir daí, buscarmos a compreensão dos cursos hoje oferecidos e consequientemente fazer sentido à Universidade Operacional de Chauí.

\section{A FORMAÇÃO DE PROFESSORES NAS ÚLTIMAS TRÊS DÉCADAS}

Com este texto, pretendemos, de forma sintetizada, apenas situar o que vem acontecendo em torno dos cursos de formação de professores nas ultimas três décadas para que a partir de então possamos pensar na contemporaneidade e nas questões que circundam o papel das instituições de ensino superior frente à formação de professores, e claro, frente ao desafio de "formá-los" para atuar na Sociedade da Informação ou

\section{Digital.}

Durante a década de 70, devido à forte presença da Tendência Tecnicista na educação advinda da década anterior a esta, o processo de formação de professores estava muito voltado para a instrumentalização, privilegiando assim toda uma dimensão

6 Chauí, M. A universidade operacional. Folha de São Paulo, Caderno Mais! Maio de 1999. 
técnica sobre influência da tecnologia educacional ${ }^{7}$. Para Candau (1982), a grande preocupação no que se refere à formação de professores era justamente esta instrumentalização técnica que dava primazia ao uso cada vez mais crescente de uma racionalidade instrumental-técnica. Nesta concepção de racionalidade, a idéia de se adquirir "pacotes prontos" de fácil aplicação e resultados imediatos era uma das principais funções da educação. Segundo a mesma autora, em meados da década de 70 , passou-se a pensar uma outra vertente sobre a formação de professores: a educação passa a ser vista como uma prática social em íntima conexão com o sistema político e econômico vigente. Assim, os cursos de formação de professores passam a se basear fundamentalmente nos seus aspectos funcionais e operacionais. ${ }^{8}$ Não se pode negar, portanto, que foi a partir desta década é que se passou a pensar e analisar o uso das tecnologias educacionais como proposta pedagógica a ser inserida tanto na formação de professores quanto na prática docente. Mesmo de forma equivocada e sem muito sucesso durante esta década, vivenciamos hoje a volta dessa discussão, o que vem a ser exatamente o nosso alvo neste trabalho.

O final da década de 70 e início da década de 80 foi marcado por uma série de debates a respeito da formação docente. A educação passou a ser pensada em função das classes sociais e populares e em consequiência disso, ampliou-se a discussão sobre os cursos de formação de professores. Começaram, portanto a aparecer os vários indícios de uma crise na educação brasileira uma vez que se passaram a vincular problemas na formação dos professores às dificuldades gerais enfrentadas pela educação na nossa sociedade.

Segundo Gadotti (1998):

Nos anos 80 a educação popular ultrapassa o nível da comunidade e do poder local, a educação de adultos e a educação não formal, para influir diretamente nos sistemas educacionais públicos e estabelecer-se como educação pública popular.

Nesta década, foram muitas as transformações no sistema de ensino: aumento da oferta do número de vagas na rede pública de ensino, expansão da rede de ensino, porém esses aumentos não foram acompanhados de investimentos por parte do governo na área educacional. Isto acarretou uma série de problemas na educação na década de

7 A presença da tecnologia educacional e a discussão mais sistematizada sobre o assunto nas instituições educacionais foi iniciada no Brasil a partir dos anos 60. A sua utilização naquele momento era fundada no tecnicismo. SAMPAIO, 2001.

$8 \quad$ CANDAU, Vera Maria Ferrão (coord). Novos rumos da licenciatura. Brasília: INEP, 1987, p.93. 
80, e, tais problemas se prolongaram até os dias atuais.

Para Gadotti (1998), "Houve uma deteriorização da educação: privilegiou-se a quantidade e não a qualidade; a educação como mercadoria incentivou a privatização do ensino".

Privatizar o ensino reforça o pensamento da divisão do que vem a ser ensino de qualidade. Houve a partir daí não apenas o fortalecimento da rede privada de ensino como também reforçaram as desigualdades sociais, principalmente educacionais. Diante deste crescimento quantitativo, houve necessidade de maior número de professores. Para atender a demanda da época valia-se de tudo: do professor leigo, o aumento dos cursos de licenciaturas em faculdade isoladas, etc.

Segundo Cury (1982) “o professor foi sendo paulatinamente esvaziado dos seus instrumentos de trabalho: do conteúdo (saber), dos métodos (saber fazer), restando-lhe agora, quando muito, uma técnica sem competência".

Nesta perspectiva, o final da década de 70 e início da década de 80 foi marcado pela própria banalização do magistério: o exercício da docência como bico ${ }^{9}$, a falta de profissionais formados para exercer a docência, o crescente número dos chamados professores leigos. Já que na década de 80 a função era educação na prática social, a docência passou a ter uma responsabilidade que ultrapassava a competência técnica, para agregá-la à consciência e exercício da competência política e social. Passou-se a pensar na relação teoria e prática. Diante desta relação, muitas críticas circundaram o eixo das discussões a nível superior de ensino. Até então, a relação teoria e prática era esvaziada de fundamentos, pois cabia à universidade o papel de realizar e difundir o resultado de pesquisas, enquanto isso, cabia ao professor apropriar-se das pesquisas produzidas e saber aplicá-las cotidianamente. Havia nesta perspectiva um distanciamento entre quem "pensa" a educação e entre quem "pratica" a educação, ou seja, quem produz a teoria e quem se apropria da mesma para aplicá-la em sala de aula. A universidade não demonstrou assim sua função de "formar educadores".

Segundo Pereira (2002):

O que se ouve, então, é um grito indignado por parte da comunidade acadêmica em relação ao descaso das universidades brasileiras com as questões que envolvem o ensino de gradação e, especialmente, os cursos de formação docente. Ressalta-se nessas falas situação de menos prestígio acadêmico das licenciaturas em relação aos cursos de formação de pesquisadores e essa discussão voltará a ocorrer nos anos 90, levantando a questão do ensino e da pesquisa na universidade e seus reflexos nos cursos de formação profissional.

9 Metáfora atribuída para inserir a intenção de reforçar o descompromisso profissional. 
Entrando agora na década de 90, o que se pode perceber é que a mesma é marcada pela relação ensino-pesquisa na formação de professores. Pensa-se agora no professor como questionador e ao mesmo tempo construtor de sua prática docente. O professor nesse momento é um pesquisador. Incentiva-se agora a formação continuada e a capacitação em serviço em detrimento da antiga reciclagem.

Segundo Tardif (2002), "o saber é um construto social produzido pela racionalidade concreta dos atores, por usar deliberações, realizações e motivações que constituem a fonte de seus julgamentos, escolhas e decisões".

Ainda este mesmo autor afirma que existem duas teses sobre os saberes docentes: na primeira os professores são sujeitos do conhecimento e possuem saberes específicos ao seu oficio; na segunda tese, a prática deles, ou seja, seu trabalho cotidiano, não é somente um lugar de aplicação de saberes produzidos por outros, mas também um espaço de produção, de transformação e de mobilização de saberes que lhe são próprios.

Para Contreras (2000):

\begin{abstract}
Não é possível falar de autonomia de professores sem fazer referência ao contexto trabalhista, institucional e social em que os professores realizam seu trabalho. ..é importante ter isso claro, porque a perspectiva de autonomia dos professores mudou nos últimos tempos, tanto no que se refere à literatura pedagógica, quanto as formulações políticas sobre a educação e o trabalho dos professores.
\end{abstract}

Mas ainda temos muito a pensar. Na contemporaneidade do século XXI, a educação se encontra em uma grande encruzilhada: de um lado, o desempenho do sistema escolar não tem dado conta da universalização da educação básica de qualidade e nem mesmo de erradicar um problema crucial que ocorre principalmente nos países de terceiro mundo que é o analfabetismo; de outro, as teorias e concepções pedagógicas clássicas e novas não apresentam a consistência global necessária para indicar caminhos realmente seguros numa época de profundas e rápidas transformações que estão ocorrendo não somente no eixo das instituições escolares, mas em toda a sociedade.

\begin{abstract}
A educação opera com a linguagem escrita e a nossa cultura atual dominante vive impregnada por uma nova linguagem, a da televisão e a da informática. Os sistemas educacionais ainda não conseguiram avaliar o poder da comunicação audiovisual e da informática, seja para informar, seja para bitolar mentes. Trabalhamos ainda com recursos tradicionais que não tem apelo para crianças e jovens. É preciso mudar profundamente os métodos de ensino para reservar ao cérebro humano o que lhe é peculiar - a capacidade de pensar - em vez de desenvolver a memória. Para isso é preciso dominar a linguagem, inclusive a linguagem eletrônica.(GADOTTI, 1998).
\end{abstract}

Pensar, portanto, nos cursos de formação de professores requer pensar políticas públicas voltadas para isto. Na verdade, a grande inquietação nos dias atuais é que esta 
nova geração, mesmo não tendo computador em casa, já está de alguma forma "antenada" com algum tipo de recurso tecnológico, seja o videogame, sejam os bichinhos virtuais (que custam muito barato e todos podem ter acesso), seja pela própria mídia de massa. Desta forma, esta nova geração estará exigindo cada vez mais um outro tipo de comportamento advindo da escola. Esta geração é bem diferente da geração dos nossos avós, onde a educação se fazia apenas por transmissão, e hoje, a mera transmissão se tornou inaceitável.

Mesmo sem ter acesso às mais diversas tecnologias, o professor tem que saber o que é cibercultura, sociedade da informação, sociedade digital, AlTv, ou seja, ele tem que ter consciência do que é a sociedade contemporânea para que ele possa atuar na mesma. Caso isto não aconteça, o professor estará cada vez mais distante do seu alunado e desta forma, a escola se tornará cada vez mais chata ${ }^{10}$ (SILVA, 2003).

\section{A INFORMAÇÃO E AS MÚLTIPLAS LINGUAGENS ADVINDAS DA COMUNICAÇÃ̃O: A FORMAÇÃO DO PROFESSOR CRÍTICO DIANTE DAS INFORMAÇỔES E DAS TECNOLOGIAS.}

A inserção da qual falávamos anteriormente não se limitará somente ao uso de recursos. Integrar as TICs na ação docente requer um vôo mais alto. É preciso integrar e criticar as TICs principalmente no que se refere à acessibilidade ao grande volume de informações. O professor passa a ter agora a necessidade de adquirir o entendimento das múltiplas linguagens: a linguagem multimídia, polifônica, virtual, cooperativa, recíproca. Afinal, para que tudo isto? O trabalho docente não mais se limitará ao repasse das informações, pois, as informações estão por aí nos mais diversos veículos midiáticos: tv, rádio, imprensa, internet, dentre outros. Não precisamos de ninguém para repassar informações, pois as fontes são acessíveis, muitas vezes dinâmicas e bem mais interessantes do que o estabelecimento do próprio diálogo.

É importante ressaltar aqui, que as questões relacionadas à comunicação e informação ganharam muito espaço principalmente depois da maior acessibilidade à internet. A partir de então, vários conceitos foram sendo desenvolvidos, como por exemplo, os conceitos de interação e interatividade. Distinguindo então estes dois conceitos, temos que, a interação ocorre sem que exista uma predisposição para isto. $\mathrm{O}$ simples fato de nos depararmos com alguém, seja para repassar, dialogar ou transmitir

\footnotetext{
10 Professor da Estácio de Sá em participação no Programa Salto para o Futuro - série: Integração das mídias. Canal TV Escola. Programa veiculado dia 20 de novembro de 2003 no horário das 11:00 às 12:00 horas.
} 
já significa que ocorre interação. Já a interatividade, que é uma palavra que está "na moda" e que não é um conceito criado a partir da informática, mas foi ela quem soube melhor se apropriar do mesmo, significa buscar alcançar o mais comunicacional, ou seja, interagir significa não apenas repassar ou transmitir, mas, a partir do momento em que isso ocorre, espera-se uma troca, uma resposta ou pelo menos um estímulo (ibdem).

Diante disso encontramo-nos frente a um novo papel, por sinal bastante desafiador, importe ao trabalho docente: criticar as informações, filtrá-las, intervir no aprendizado provocado por elas e, principalmente, transformar estas informações em conhecimento. Este é um dos pontos cruciais: fazer a leitura crítica das mídias não requer somente habilidade. Requer, antes de tudo, a junção de vários hábitos: impessoalidade, ética, conhecimento, pluralidade e, o principal de todos, o hábito da leitura crítica.

Em países como o Brasil, onde o hábito da leitura é escasso, falar em leitor crítico das mídias requer uma atenção especial à definição das mídias. Afinal, de que mídias estamos falando?

O importante aqui não é definir a mídia alvo para procurarmos uma resposta. Levaremos em consideração todas as fontes por onde chegam as informações. Devemos ficar bem atentos quanto a essa questão, uma vez que as mídias, sejam massivas ou interativas, resultam em um grande esforço mental para serem analisadas criticamente.

No entanto, o discurso feito até aqui traz consigo inquietações consideráveis que permeiam dentre os mais diversos níveis de ensino. Se as tecnologias não invadem o ambiente escolar, para que discutirmos sobre elas? Retomo aqui a pergunta feita como título deste trabalho: A formação de professores relacionada à ação docente mediada pelas tecnologias de informação e comunicação: afinal, para que tecnologias?

Esta é uma pergunta ainda em discussão e sem resposta plausível aos segmentos escolares. Negligenciar a existência ou ignorar a necessidade de seu uso significa adotar uma postura antidialética da educação e passar a ver a escola como algo pronto e imutável. A sociedade em constante estado de mutação requer, porém uma outra postura advinda da escola.

O mundo virtual possui várias linguagens, mas a escola não pode aderir ao esquema das "tribos" $" 11$ adotando as várias linguagens subentendidas usadas por um determinado grupo para se comunicar. Há que se considerar que a comunicação, como

$11 \quad$ Metáfora atribuída aos grupos que adotam as mesmas linguagens para se comunicar. Por exemplo, os sinais utilizados nos correios eletrônicos, na maioria das vezes, são adotados por um certo grupo que entende e se comunica através daquela linguagem. 
um processo tão antigo quanto à existência do próprio homem, sofre e vem sofrendo alterações enquadradas em seus mais diversos contextos. Mas a escola, como sistema norteador e inter-relacionado com a sociedade na qual está inserida, deve estabelecer padrões de linguagem pelo menos assemelhados, pois acredita-se que, tendo a própria escola caído em contradição quanto à construção de seus conceitos, ela estará fadada ao mesmo destino que tomaram as diversas tentativas de normatizar um ensino padrão e a educação para todos. É preciso respeitar a diversidade. (Daniel, 2003) ${ }^{12}$.

Portanto, a normatização requer ainda um outro tipo de consciência: a consciência política.

As múltiplas linguagens presentes na sociedade "digitalizada" não devem servir de parâmetro para o avanço da "exclusão dos já excluídos". Cabe, portanto à escola estabelecer uma linguagem única para garantir a democracia e o acesso de quaisquer cidadãos. Por esse motivo, exige-se a consciência política: estabelecer uma linguagem democrática em eras de modernização, informatização e automação, torna-se uma função a ser desenvolvida com grande urgência, pois se pode, a partir daí, tornar possível reduzir a discrepância existente entre os sistemas educacionais.

Se colocarmos então o nosso alvo de estudo, a formação e a ação docente no eixo dessa intriga, chegaremos a uma conclusão: a integralização das tecnologias de informação e comunicação nos cursos de formação de professores (seja formação inicial ou formação continuada) é o ponto de partida destas transformações.

Para Belloni (2001):

\begin{abstract}
Os desafios que estas mudanças na estrutura das demandas sociais de educação pós-secundária (formação inicial e continuada) significam para os sistemas educacionais são enormes: de um lado, na formação inicial, será preciso reformular radicalmente currículos e métodos de ensino, enfatizando mais a aquisição de habilidades de aprendizagem e a interdisciplinaridade (o que implica diminuir a quantidade de conhecimentos), sem, no entanto negligenciar a formação do espírito cientifico e das competências de pesquisa; de outro, as demandas crescentes de formação ao longo da vida terão que ser atendidas.(grifos da autora)
\end{abstract}

E é nesta perspectiva que a educação superior deve se respaldar. Os cursos de formação de professores terão que dar respostas às exigências desta sociedade. A sociedade da informação surge na década de 70 devido a uma revolução tecnológica sem precedentes. Houve a partir de então uma rápida passagem da sociedade industrial à sociedade informatizada. Toda a revolução advinda através das mais variadas

12 Reunião de Ministros Nórdicos, Oslo, 3 de junho de 2002. Texto publicado no livro Educação e Tecnologia num mundo globalizado. 
transformações, incluindo aqui o sistema capitalista, ganhou ênfase na medida em que a sociedade se tornava cada vez mais consumista e consequientemente produtiva.

O que se pode notar é que, a partir de então, a grande força do capitalismo unida ao processo de globalização, provocou um dualismo nessa sociedade.

Em educação, essa dualização é concretizada no fato de que a sociedade da informação prioriza o domínio de certas habilidades. As pessoas que não possuem as competências para criar e tratar a informação ou aqueles conhecimentos que a rede valoriza, ficam excluídas. (TARTOJADA, 2000).

Mais uma vez as tecnologias afetam diretamente a educação. Mas é preciso refletir que essa dualidade, imposta pelos novos meios de produção e pelo fortalecimento do capitalismo não se constitui em nenhuma novidade para os educadores. A dualidade educacional ${ }^{13}$ é tão antiga quanto o próprio conceito de educação, principalmente no Brasil. O que deve ser considerado é que através desses avanços estão sendo criadas novas dualidades, e, conseqüentemente, está se formando agora uma nova geração de analfabetos: o analfabeto digital.

Esse ponto torna-se crucial na medida em que a própria educação não consegue atender às expectativas do seu alunado. Por isso, pensar a educação requer investir em pesquisa na área. Pesquisar pode ser uma saída para a implementação de uma nova concepção de formação de professores que venha a atender todos os anseios.

Mas nós, educadores, ainda trabalhamos erroneamente diante das nossas próprias concepções de ensino. Temos ainda uma visão limitada sobre o uso das tecnologias na educação e suas possíveis contribuições para a melhoria do processo ensino-aprendizagem. Investir na formação de professores, seja formação inicial ou continuada, é um dos fatores primordiais para se procurar instigar uma mudança tanto conceitual quanto prática.

Repensar a formação e a ação docente pode proporcionar uma nova visão da utilização das tecnologias educacionais. A contribuição que os cursos de formação de professores tem a oferecer é imensa: é preciso estimular, orientar, criar e inovar propostas, unir as novas e as velhas tecnologias, fazer da escola um ambiente de reflexão da própria prática docente, o que Lévy (1999) nos coloca de forma muito clara dizendo que:

13 A nomenclatura "dualismo educacional" ficou popularmente concretizada na década de 70, com a aprovação da lei 5692/71, a qual regulamentou os cursos de formação técnica em nível médio de ensino. O chamado "dualismo" caracterizava a divisão da sociedade em dois pólos: o primeiro daqueles que iriam concluir o ensino secundário e seguir carreira nos cursos superiores e o segundo daqueles que faziam parte da camada economicamente menos favorecida que iriam fazer cursos técnicos para ingressar no mercado de trabalho e atender as exigências da mão-de-obra qualificada e barata. 
É preciso colocar as pessoas nessa situação de curiosidade, nessa possibilidade de exploração. Não individualmente, não sozinhas, mas juntas, em grupo. Para que tentem se conhecer e conhecer o mundo a sua volta. E, uma vez compreendido esse principio de base, todos os meios servem, os meios técnicos servem. Os meios audiovisuais, interativos, os mundos virtuais, os grupo de discussão, tudo o que quisermos (LÉVY apud KENSKI, 2001).

A importância que isso representa na formação do professor traz contribuições não somente à escola, mas à sociedade na qual a mesma está inserida, uma vez que a integração dos professores em uma nova ação docente mediada pelas tecnologias gera o desejo de participar do processo de intercâmbio de conhecimentos, a vontade de apresentar contribuições originais, transmitir e trocar idéias, de forma cooperativa e aberta. Isto significa incentivar e estimular a busca por uma educação que atenda e seja compatível com os anseios da sociedade. Pois segundo Lévy (ibdem), "quem aprende mais e mais depressa são as crianças mais novas". Isto ocorre porque elas têm um instinto de curiosidade, de busca, não sentem medo de errar e são mais abertas a receber aquilo que para elas é novidade. Talvez, seja isto que esteja faltando aos professores: coragem e não ter medo de errar.

Pretendemos encerrar este trabalho, ressaltando que as tecnologias na educação são apenas tecnologias. Elas não falam por si, elas não agem sozinhas, elas não funcionam sem planejamento, e, por esse motivo, para lidar com as mesmas deve haver preparação e formação docente propícia a isso.

Como diz Penteado (1998)

Todavia é preciso considerar que a simples presença desses recursos no trabalho pedagógico não é sinônimo de mudanças significativas na qualidade de tal trabalho. Inicialmente é preciso lembrar que as novas tecnologias comunicacionais são apenas e tão-somente prolongamentos refinados, recursos sofisticados, aptos a potencializar a capacidade comunicacional inerente ao ser humano, que o caracteriza como animal social por excelência e produtor de cultura. Portanto, será tão somente na vivência de uma didática que exercite a capacidade comunicacional humana e pratique a educação como um processo específico de comunicação que as tecnologias comunicacionais ganharão a possibilidade de exercer o seu poder transformador, rumo a uma educação escolar formadora, reveladora, suporte para o exercício pleno da verdadeira cidadania. 


\section{REFERÊNCIAS}

BARRETO, R. G. (org). Tecnologias educacionais e educação a distância: avaliando políticas e práticas. Rio de Janeiro: Quarter, 2001.

, Formação de professores, tecnologias e linguagens: mapeando velhos e novos (des) encontros. São Paulo: Loyola, 2003.

BELLONI, M. L. O que é mídia educação? Campinas : Autores Associados, 2001.

(org), A formação na sociedade do espetáculo. São Paulo: Loyola, 2002.

, O que é educação a distância?. Campinas : Autores Associados, 2001.

CANDAU, V. M. F. (coord). Novos rumos da licenciatura. Brasília: INEP, 1987.

, A formação de educadores: uma perspectiva multidimensional. Em aberto.

Brasília, v.1, n.8, p. 19-21, ago. 1982.

CHAUÍ, M. A universidade operacional. Folha de São Paulo, Caderno Mais! maio de 1999.

CONTRERAS, J. A autonomia de professores. São Paulo: Cortez, 2000.

CURY, C. R. J. Notas acerca do saber e do saber fazer da escola. Cadernos de Pesquisa, São Paulo, v.40, p.58-60, fev. 1982.

DANIEL, J. Educação e tecnologia num mundo globalizado. Brasília, Unesco, 2003.

DELVAL, J. Teses sobre o construtivismo. In: ARNAY, José. RODRIGO, M. J. (orgs). Conhecimento cotidiano, escolar e cientifico: representação e mudança. 2.ed. São Paulo: Ática, 2002.

GADOTTI, Mr. Pedagogia da práxis. São Paulo: Cortez, 1998.

KENSKI, V. M. Em direção a uma ação docente mediada pelas tecnologias digitais. In: BARRETO, R. G. (org.) Tecnologias educacionais e educação a distância: avaliando políticas e práticas. Rio de Janeiro: Quarter, 2001.

Tecnologias e ensino presencial e a distância. Campinas: Papirus, 2003.

LÉVY, P. As tecnologias da inteligência: o futuro do pensamento na era da informática. Rio de Janeiro: Editora 34, 1993.

MORAN, J. M; MASETTO, M. T.; BEHRENS, M. A. Novas tecnologias e mediação pedagógica. Campinas: Papirus, 2001. 
PENTEADO, H. D. (org). Pedagogia da comunicação: teorias e práticas. São Paulo: Cortez, 1998.

PEREIRA, J. E. D. Formação de professores: pesquisa, representações e poder. Belo Horizonte: Autêntica, 2000.

PRETTO, N. de L. Uma escola sem/com futuro. Campinas: Papirus, 2002.

SAMPAIO, M. N.; LEITE, L. S. Alfabetização tecnológica do professor. Petrópolis: Vozes, 2001.

SOUZA, C. H. M. de. Comunicação, educação e novas tecnologias. Campos dos Goytacazes. Rio Janeiro: FAFIC, 2003.

. Do lugar ao não lugar: a re-invenção do conhecimento. Revista

Interscienceplace. Ano I, n. 01.Disponível em:

http://www.interscienceplace.org/downloads/resumo12.pdf , 2008.

TARDIF, M. Saberes docentes e formação profissional. Petrópolis: Vozes, 2002.

TARTOJADA, I.; FLECHA, R. Desafios e saídas educativas na entrada do século. In: IMBERNÓN, F. (org). A educação no século XXI: os desafios do futuro imediato. Porto Alegre: B Artmed, 2000. 